\title{
A escrita histórica do teatro: reflexões sobre o fazer historiográfico
}

\section{The historical writing in theatre: a reflection on historiographical process}

José Denis de Oliveira Bezerra ${ }^{1}$ 


\section{Resumo}

Este artigo se propõe a refletir sobre a temática da escrita da história do teatro brasileiro, e se pauta na experiência com a pesquisa documental, procurando debater, também, o uso de fontes e seu lugar na historiografia. Para esse objetivo, o texto dialoga com debates apresentados por Brandão (2010), sobre as lacunas e séries nas histórias do teatro brasileiro; e Certeau (2011), acerca dos conceitos e formas sobre escrita da história. Diante de tantas questões que o tema suscita, pretende-se, nesse texto, contribuir com os debates presentes nesse campo de investigação, a partir da experiência com os estudos sobre produção teatral em Belém do Pará.

Palavras-chave: Historiografia; Teatro Brasileiro; lacunas; documentos

\section{Abstract}

This article proposes a reflection on the theme of Brazilian theatre historical writing. It is based upon document research and also upon discussion of sources and their place on Brazilian historiography. We take into account Brandão (2010), on the gaps in Brazilian theatre history, and Certeau (2011), on concepts and framework of historical writing. By recognizing questions that arise from this subject, we intend to contribute to the discussions presented in this research field from the perspective of our research experience on theatre production in the city of Belem do Para (Brazil).

Keywords: Historiography; Brazilian theatre; gaps; document 
O demônio da memória também não colaborou em nada, poderia liberar meu passado, poderia tocar com a varinha de condão e dizer: Saiam reminiscências. (Antônio Brasileiro apud Jerusa Ferreira-Armadilhas da Memória).

Escrever sobre práticas artísticas e culturais requer um exercício de fôlego e construção de redes interpretativas. O trabalho do historiador é árduo, ele submerge nos labirintos do esquecimento, dos silêncios e das recordações, na busca de pensar a sociedade, composta por seus elementos históricos, alimentados pelas memórias. A atenção do pesquisar se volta para as trocas culturais, simbólicas, compostas pelas memórias individuais e coletivas, que como uma colcha de retalhos se juntam, guardam as particularidades, mas costuradas representam, também, outros organismos.

Sujeitos históricos se constroem em trocas simbólicas, no enfrentamento de pensamentos, na difícil relação de alteridade. Dessa maneira, percebo que o contato com a história cria um vínculo com o meio social, com as relações que se estabelecem entre os atores sociais e suas ideologias, crenças, valores, que se fazem representados por meio de signos-poder para a manutenção das posições sociais de cada grupo. Por isso, refletir sobre a construção da história de um povo, de um grupo e as experiências de indivíduos, torna-se importante para o autoconhecimento da sociedade.

Os estudos da memória foram o meu primeiro contato com as perspectivas sobre o valor que os atos do passado possuem ao se relacionar com a materialidade do presente. Por isso, as reminiscências das artes de minha cidade me levaram a antanho, ao porto de partida por onde as naus do tempo navegam pelo rio de Lethe, resistem aos seus desvios e comungam com os novos horizontes, que o navegador encontra a cada parada em um cais. E esse percurso se iniciou com os ventos das vozes que procurei, para a travessia ao ontem².

O simples ato de parar e ouvir, inicialmente impulsionado pelo desejo de não se deixar olvidar as memórias da arte teatral de Belém do Pará, colocou-me diante de histórias de vidas, representantes de pensamentos e práticas coletivas. Mas, sobretudo, pôs-me ao ensinamento da tradição, pela voz da experiência. A coletividade social ${ }^{3}$ reverberou-se nos testemunhos individuais de narradores de um tempo, situados em espaços físicos, simbólicos e, concomitantemente, percorridos pelos "becos" das reminiscências.

Porém, como reflexo da própria sociedade em que vivemos, a matéria orgânica e sígnica da voz confrontou-se com a presença da escrita. Aos poucos, ao adentrar no universo da pesquisa sobre o teatro produzido no Pará, os testemunhos projetados pela oralidade dividiram espaço com o exercício intelectual da palavra grafada. Os relatos em história oral ${ }^{4}$ não sumiram, mas as narrativas impressas em jornais, cartas,

\footnotetext{
${ }^{2} \mathrm{O}$ primeiro contato com a pesquisa histórica sobre o teatro paraense partiu do contato com estudos da memória e com o método da História Oral. Isso foi motivado porque as poucas referências bibliográficas não abordavam o tema que pretendia investigar; e, também, a partir do contato com as entrevistas realizadas com artistas de Belém, tive a necessidade de estudar alguns fenômenos relatados por eles e que a historiografia, então existente, não tinha discutido sobre 0 assunto.

${ }^{3}$ Maurice Halbwachs (2003, p. 39), em seu estudo sobre "memória coletiva", defende que lembranças, reminiscências só ocorrem em atos coletivos, em grupos: "para que nossa memória se aproveite da memória dos outros, não basta que estes nos apresentem seus testemunhos: também é preciso que ela não tenha deixado de concordar com as memórias deles e que existam muitos pontos de contato entre uma e outras para que a lembrança que nos fazem recordar venha a ser reconstruída sobre a base comum".

${ }^{4}$ Em minha dissertação de mestrado, discuto a necessidade de utilizar como método para a coleta de fontes a História Oral. Além de perceber as lacunas que a historiografia do teatro brasileiro com relação a produção teatral paraense, os livros de história do teatro local não abordavam o recorte e o objeto proposto na pesquisa, de forma sistemática, como desejava. Dessa maneira, o capítulo dedicado a essa discussão, "O teatro no Pará: da lacuna histórica à necessidade
} 
livros e outros conquistam, cada vez mais, espaço nos discursos históricos sobre as práticas teatrais.

É a partir dessa experiência com a pesquisa histórica sobre o teatro paraense, que esse artigo surge, para debater os caminhos metodológicos e uso de fontes diversas; e o exercício da escrita historiografia sobre a produção teatral, em Belém do Pará. Com isso, busca-se contribuir com os debates acerca da pesquisa e registro dos teatros brasileiros.

\section{As lacunas e os lugares do discurso}

As discussões sobre a historiografia do teatro brasileiro é um tema recorrente entre estudiosos e suscita alguns pontos para debates. Entre eles é a conceituação do termo nacional, na tentativa de dar conta de uma narrativa histórica. Brandão (2010) traz uma reflexão crucial para os estudos da história e da historiografia do teatro brasileiro, ao apresentar dois conceitos fundamentais, ao meu ponto de vista, para os pesquisadores da área: a ideia das lacunas e das séries.

A historiadora apresenta, primeiramente, a discussão sobre a necessidade de se construir uma história monumental, desejo e anseio dos estudiosos que já se dedicaram a tal empresa: "necessária falta de uma histórica monumental, associável também a muitas variáveis a considerar, impõe a indicação de que sua falta é preenchida com a ocorrência dominante de histórias fragmentárias." (Brandão, 2010, p.336).

Somado à ideia de história monumental como uma narrativa abrangente, totalizante, a concepção de Le Goff (2003, p.526) nos possibilita a refletir sobre a produção da historiografia do e/ou sobre o teatro produzido no Brasil. Ele afirma que "o monumento tem como características o ligar-se ao poder de perpetuação, voluntária ou involuntária, das sociedades históricas (é um legado à memória coletiva) e o reenviar a testemunhos que só numa parcela mínima são testemunhos escritos". Essa ideia de monumento possibilita dizer que o exercício da escrita histórica teatral representa esse duplo caminho: primeiro, o desejo de compartilhar as experiências de artistas e da sociedade com a arte; segundo, exerce um poder, o de organizar e perpetuar esses saberes por meio da escrita.

Além desse aspecto, surge um ponto fundamental: os estudos de história do teatro brasileiro dedicaram-se muito mais à literatura dramática ao invés de "estudos sobre o teatro, sua diversidade, seus procedimentos, mecanismos, conceitos, imagens, motores, personalidades e acontecimentos" (Brandão, 2010, p.337). Essa questão parte do atrelamento das práticas cênicas brasileiras à uma vida literária, quando escritores e intelectuais, atuantes na literatura e crítica, articularam ideias sobre a arte dramática ${ }^{5}$.

Sobre a adjetivação "brasileiro", Brandão (2010, p.337) destaca que no século XIX o Rio de Janeiro era o centro cultural do império, e que questões de ordem socioeconômica, que se articulavam da corte para as províncias, a partir de "uma

da memória", procura fundamentar a importância dos estudos da memória na construção da história do teatro. Sobre isso ver: Bezerra (2013). Na pesquisa de doutorado, a pesquisa documental passou a direcionar a escrita da história do teatro em Belém.

${ }^{5}$ Alguns livros que abordam a história do teatro brasileiro, a partir da literatura dramática, podem ser citados aqui: Sábato Magaldi. Panorama do Teatro Brasileiro. Rio de Janeiro: Serviço Nacional de Teatro/ FUNARTE, 1979; Décio de Almeida Prado. História Concisa do Teatro Brasileiro: 1570-1908. São Paulo: Edusp, 2008; Gustavo Doria. Moderno Teatro Brasileiro. Rio de Janeiro: MEC/SNT, 1975. 
dinâmica agroexportadora escravista", proporcionou a centralização das práticas teatrais brasileiras como cortesãs, segundo a autora, portanto, "uma prática carioca".

Contudo, a historiadora pontua que o fato do Rio de Janeiro ser um centro irradiador da produção cultural, e dele, segundo a autora, as províncias procuravam criar um elo de encontro com a corte, "esta situação não deveria ser um salvo-conduto para que os pesquisadores reproduzissem automaticamente o modelo de dominação e excluíssem a história local" (Brandão, 2010, p.338). Na verdade, os outros centros de poder socioeconômico brasileiros mantinham intensas atividades culturais, que refletiam os modos de vida de cada lugar. Aqui, posso falar da capital paraense.

Belém, da segunda metade do século XIX ao início do XX (1912), vivenciou, proporcionado pela economia da borracha, um período de transformações em seu espaço urbano, no modo de vida das novas classes dirigentes, o que ficou conhecida como a bela época amazônica6. Com isso, a produção cultural também passou por transformações. Na área do teatro, ocorreu a construção do Theatro da Paz ${ }^{7}$, junto com o Teatro Amazonas de Manaus, o mais importante centro cultural da Amazônia. Por essa casa de espetáculos apresentaram-se artistas nacionais e, principalmente, estrangeiros (a França passou a ser o modelo principal e suas obras e artistas circularam pela capital paraense durante esse período), e fortaleceu o chamado teatro musicado, com os gêneros diversos, primordialmente a ópera ${ }^{8}$.

Esse breve painel é para demonstrar que mesmo que o Rio de Janeiro fosse o centro econômico e cultural do sudeste do Brasil, na Amazônia havia uma intensa produção que mantinha relações mais com a Europa (devido às questões espaciais e comerciais) do que com a Capital Federal. É evidente que essas relações políticas existiam, porém, o teatro em Belém, certamente como nas demais regiões do Brasil, se organizava de acordo com as suas próprias necessidades. Todavia, ressalta-se que mesmo diante dessa realidade particular, a crítica e a intelectualidade da época dedicou atrelar-se mais ao Rio de Janeiro do que se voltar para os fatores locais, com raríssimas exceções.

Contudo, sobre a necessidade de produção de uma historiografia do teatro brasileiro, Brandão (2010) destaca que as publicações representam um esforço de intelectuais para a construção de uma narrativa histórica, porém, elas não deram conta de falar, como muitas se propuseram, da diversidade cultural do país:

As histórias do teatro brasileiro disponíveis formam uma lista pequena e apresentam, em sua formulação, um desenho muito peculiar, em que a longa duração aparece casada com uma forte exclusão. O território da exclusão é extenso: remete ao conceito de tempo pouco problematizado, à definição restrita de teatro adotada e ao contorno arbitrário do nacional, este último identificado como brasileiro mecanicamente, mas essencialmente carioca e por vezes também paulista, com uma forma de referendo ao centro de poder e comando, eco da história econômica-política (Brandão, 2010, p.338).

\footnotetext{
${ }^{6}$ Sobre essa questão, ver: Maria de Nazaré Sarges. Belém: riquezas produzindo a Belle Époque (1870-1912). 3ed. Belém: Paka-Tatu, 2010.

${ }^{7}$ Sobre os primeiros 25 anos de vida desse teatro, ver: Rose Silva. Histórias invisíveis do Teatro da Paz: da construção à primeira reforma. Belém do Grão-Pará (1869-1890). Belém: Paka-Tatu, 2010.

${ }^{8}$ Ver: Salles (1980); e Salles (1994).
} 
Esse problema da nacionalidade é um tema importante na reflexão sobre a produção historiográfica do teatro brasileiro. Brandão (2010) destaca que para se fazer um estudo sobre a História do Teatro Brasileiro é necessário considerar as possibilidades de caminhos analíticos, pois diante desse fato "delimita-se um campo de trabalho claro - é possível localizar padrões peculiares na historiografia destas histórias do teatro brasileiro. Trata-se de uma historiografia em que dois procedimentos se repetem infinitamente, sob múltiplas formas: as lacunas e as séries (Brandão, 2010, p.338).

Porém, além da problemática presente no conceito de nacional, os livros de história e historiografia teatral brasileira, quando surgem, se dedicam a espaços urbanos historicamente eleitos como centro irradiadores de formas, gêneros e gostos. Surge, aqui, portanto, a necessidade de se problematizar as relações de poder presentes nesses espaços de produção intelectual. Quando um historiador se coloca nesse lugar de fala e toma o seu lugar para produzir um discurso totalizante ou monumental, ele assume uma postura de poder. É necessário, portanto, nos estudos históricos contemporâneos sobre o teatro no Brasil questionar essas posturas e espaços de produção intelectual.

Um exemplo disso se verifica nas produções historiográficas que se dedicam ao teatro produzido fora do chamado eixo central da cultura brasileira. As pesquisas que abordam o fazer teatral em suas cidades e estados precisam sempre localizar seu trabalho, enquanto os do centro sempre tomam uma postura metonímica, falar do particular em nome de uma totalidade que não existe. Há, sim, conexões, trocas, movência entre artistas, pesquisadores, intelectuais, experiências compartilhadas; mas, quando surge a necessidade de registro, por meio da escrita, o "centro" se coloca na frente das periferias.

A necessidade de falar das experiências particulares é um direcionamento para se construir não uma, mas diversas historiografias teatrais brasileiras. Um caminho para isso, é a expansão de pesquisas sobre esses fazeres locais, é preciso que mais estudiosos se interessem e se dediquem a tal tarefa. Para isso, as articulações entre os pesquisadores precisam se intensificar e se expandir. Podemos citar aqui alguns esforços, como a criação e manutenção de espaços de trocas e debates sobre as experiências individuais e coletivas sobre a produção científica do teatro produzido sobre e no Brasil. Dois deles são o GT Teatro e História, ligado à ANPUH ${ }^{9}$; e o GT de História das Artes do Espetáculo, da $\mathrm{ABRACE}^{10}$. Além desses lugares, os programas de pós-graduação, as revistas científicas, os cursos de graduação e os técnicos e tecnológicos contribuem para a ampliação dessa área de conhecimento.

Esse problema das lacunas e séries, aqui expostas, são um passo importante para se pensar a produção historiográfica do teatro brasileiro. Os lugares de produção crítica resultam de um intenso espaço de luta, reflete os poderes oblíquos existentes

\footnotetext{
${ }^{9}$ Em sua ementa, o GT informa a sua trajetória de constituição. Além disso, afirma: "Ela é retomada agora visando reafirmar o sentido original da nossa proposta e incorporar um maior número de pessoas interessadas em se integrar a essas discussões". Disponível em: http://www.snh2011.anpuh.org/simposio/view?ID_SIM$\mathrm{POSIO}=521$

${ }^{10}$ Criando em 2008, esse GT, ligado à Associação Brasileira de Artes Cênicas - ABRACE, informa que tem "como objetivo precípuo promover uma discussão centrada na pluralidade sobre as artes do espetáculo, levando em consideração os seus agentes constitutivos. Esses agentes do fazer e do pensar teatral são estudados do ponto de vista histórico, sociológico e estético, não havendo, portanto, nenhuma preocupação com o estabelecimento de limites geográficos, cronológicos ou temáticos nos recortes em relação aos objetos de estudo proposto pelos integrantes". Disponível em: http://portalabrace.org/1/index.php/grupos-de-trabalho/hgf/304-ementa-gt-historia-das-artes-do-espetaculo.
} 
entre o fazer, o pensar, e a circulação da arte e do conhecimento produzido sobre ela. Além disso, no trabalho com a escrita de uma história, o papel e os significados de fonte precisa ser refletido, e faremos esse exercício a seguir.

\section{Usos e experiências com as fontes na escrita historiográfica do teatro paraense/ brasileiro}

Quando me propus a escrever sobre a produção de teatro amador paraense (19411968) ${ }^{11}$, numa perspectiva da história social e intelectual, fui levado, primeiramente, a um árduo trabalho de levantamento de fontes. Essas fontes foram entendidas como objetos que fornecessem indícios sobre o que se queria debater, e, dessa maneira, entendeu-se que qualquer elemento (carta, foto, jornal, etc.) que aparecesse poderia ajudar a construir uma rede de significados sobre o tema em questão. Contudo, esses elementos, em sua maioria, fragmentados, espalhados pelo tempo e por diversos espaços, não se encontram dispostos de forma organizada, sistematizada.

O que motivava o levantamento de fontes era entender como o movimento de teatro amador e de estudante paraense ${ }^{12}$ se organizou e produziu teatro em Belém em três décadas de atividades, ou seja, a busca da renovação da cena local. Nesse desejo de investigar esse movimento de teatro na capital paraense, a experiência com a pesquisa documental foi fundamental, porque as fontes foram surgindo e indicando os caminhos metodológicos e os temas a serem debatidos. Isso ocorre porque os documentos deixam de ser apenas indícios e passam a estruturar o estudo, pois sem eles as hipóteses não são vencidas.

A minha primeira experiência com o universo histórico do teatro se deu pela pesquisa em História Oral, ao realizar entrevistas com artistas, professores e intelectuais paraenses, que pudessem me fornecer elementos para se compreender algumas "cenas" de nosso teatro. Contudo, quando comecei o trabalho com periódicos e outras fontes, a pesquisa tomou outros rumos. Iniciou-se as idas e vindas aos institutos de pesquisa, a esses lugares, oficialmente, considerados espaço de guarda e salvaguarda de documentos ${ }^{13}$.

Nesses órgãos, consegui fazer o levantamento de inúmeras fontes, como: matérias jornalísticas, anúncios e críticas de espetáculos; textos sobre a produção teatral brasileira e paraense do século XX; fotos, cartazes, relatórios, ofícios, programação de peças teatrais, e missivas. Esse "acervo" foi construído a partir do esforço de querer "descobrir" suportes que possibilitassem a reflexão de uma representação do movimento teatral amador em Belém do Pará, no século XX.

Esses documentos, para meu trabalho, significam o depoimento de um momento histórico, apesar de serem vistos, em alguns casos, como apenas registros de recordações, de diálogos entre artistas e intelectuais. Segundo Le Goff (2003, p. 526, 527):

\footnotetext{
${ }^{11}$ Ver: Bezerra (2016).

${ }_{12}$ Para isso, artistas, intelectuais e o Estado se mobilizaram na modernização dos palcos nacionais. Os discursos e os trabalhos poéticos giravam a partir de polos representativos tanto de uma tradição - formada pela presença das formas do teatro comercial, principalmente as revistas-, quanto pelas modernas obras, influenciadas por estéticas europeias, e a necessidade de reconfiguração de todo setor cultural em torno das artes cênicas.

${ }^{13}$ Em Belém, pesquisei no Arquivo Público da Biblioteca Arthur Viana, do CENTUR; na Escola de Teatro e Dança da UFPA; Museu da UFPA, arquivo Vicente Salles; na Fundação Paraense de Radiodifusão/FUNTELPA; Arquivo Central da UFPA; Arquivo da Assembleia Legislativa do Estado do Pará; e no Centro de Memória da UFPA. Fora do estado, tive a oportunidade de pesquisar no Arquivo Público da cidade de Recife/PE; na Fundação Joaquim Nabuco/PE; na Fundação Casa de Rui Barbosa/RJ; Centro de Documentação da FUNARTE/CDOC/RJ; e Biblioteca Nacional do Rio de Janeiro.
} 
O documento que, para a escola histórica positivista do fim do século XIX e do início do século XX, será o fundamento do fato histórico, ainda que resulte da escolha, de uma decisão do historiador, parece apresentar-se por si mesmo como prova histórica. A sua objetividade parece opor-se à intencionalidade do monumento. Além do mais, afirma-se essencialmente como um testemunho escrito.

Esse sentido de documento fundamenta o trabalho do historiador, que o leva a decisões de organização dos dados coletados e de sua interpretação. A historiografia do fim do século XIX e início do XX pautou-se no testemunho escrito como caminho de elucidar evidências e provas históricas. Contudo, Le Goff (2003, p. 530), mesmo ao apontar que alguns historiadores franceses ${ }^{14}$ só acreditavam que um fato histórico tivesse relevância caso houvesse registros documentais, considera que mesmo não ocorrendo a modificação da concepção de documento ${ }^{15}$ "o seu conteúdo enriquecia-se e ampliava-se".

Nessa perspectiva, o trabalho com o levantamento de fontes em espaços públi$\cos ^{16}$, sobre a produção teatral paraense, somou-se ao acesso a acervos pessoais, com fotografias, recortes de jornais, programas de espetáculos, cartazes, etc. Todo esse percurso, no levantamento de fontes, me forneceu a construção de inúmeros documentos, considerados registros de memória, que me ajudaram a construir um discurso sobre o percurso histórico acerca da produção teatral paraense no século XX. Segundo Certeau (2011, p. 72-73),

O estabelecimento das fontes solicita, também, hoje, um gesto fundador, representado, como ontem, pela combinação de um lugar, de um aparelho e de técnicas. Primeiro indício desse deslocamento: não há trabalho que não tenha que utilizar de outra maneira os recursos conhecidos e, por exemplo, mudar o funcionamento de arquivos definidos, até agora, por um uso religioso ou "familiar". Da mesma forma, a título de novas pertinências, constitui como documentos utensílios, composições culinárias, cantos, imagens populares, uma disposição dos terrenos, uma topografia urbana etc. Não se trata apenas de fazer esses "imensos setores adormecidos da documentação" e dar voz a um silêncio, ou efetividade a um possível. Significa transformar alguma coisa, que tinha sua posição e seu papel, em alguma outra coisa que funciona diferentemente.

O trabalho com a pesquisa documental, somado à organização desses elementos, nos faz refletir, também, sobre a prática da escrita historiográfica acerca da produção teatral brasileira: um caminho que nos conduz a modelos e métodos. Sempre que se inicia um projeto de uma escrita histórica sobre nosso teatro, questões importantes surgem. Entre elas, a necessidade de contemplar os lugares de produção deixados à margem. Falar do teatro requer um esforço hercúleo, porque são vários os fatores que emergem para os pesquisadores.

No momento da realização da pesquisa, a primeira questão que aparece é a necessidade de se fazer um recorte, a escolha de um tempo, de um espaço, de um

\footnotetext{
${ }^{14}$ Le Goff (2003) cita em sua análise as ideias de documento de Lefebre, em La naissance de l'historiographie moderne. Paris: Flammarion, 1971.

${ }^{15}$ Sobre isso, consultar o livro: O Historiador e suas fontes, organizado por Pinsky; De Luca (2012). Nessa coletânea, os pesquisadores se dedicam à reflexão sobre a escrita historiográfica e sua relação com documentos, ampliam a noção de fonte e apresentam estudos a partir desses registros.

${ }^{16}$ Os espaços virtuais também ajudaram no levantamento de documentos, principalmente a Hemeroteca da Biblioteca Nacional, os jornais O Estado de São Paulo, A Folha de São de Paulo, e sites de fundações nacionais e internacionais.
} 
objeto de investigação. O texto histórico já surge no exercício de seleção. Os pesquisadores se veem diante de uma ação necessária, porque seu trabalho é limitado por esses direcionamentos, mesmo que em muitos casos eles procurem dar conta do fenômeno como um todo. A escrita de uma história do teatro requer muitos movimentos, e o historiador do teatro contemporâneo, imerso em mundo plural de possibilidades teóricas, de recursos de fontes, de objetos, métodos, precisa dialogar com essa diversidade.

A delimitação de um tema torna-se primordial, quando o historiador percebe que por mais que ele tenha o desejo de abranger, precisa fazer recortes, escolhas. Há a necessidade, como afirma Certeau (2011, p. 57), de dedicar-se

[...] mais genericamente há um texto histórico (quer dizer, uma nova interpretação, o exercício de métodos novos, a elaboração de outras pertinências, um deslocamento da definição e do uso do documento, um modo de organização característico etc.) enuncia uma operação que se situa num conjunto de práticas [...] um estudo particular será definido pela relação que mantém com outros, contemporâneos, com um "estado da questão", com as problemáticas exploradas pelo grupo e os pontos estratégicos que constituem, com os postos avançados e os vazios determinados como tais ou tornados pertinentes com relação a uma pesquisa em andamento.

Uma escrita historiográfica requer organizar, separar, selecionar, recortar, redimensionar. A pesquisa em história solicita atenção a procedimentos metodológicos, principalmente no trabalho com os documentos. Certeau (2011, p. 69-70) afirma que: "em história, tudo começa com o gesto de separar, de arrumar, de reunir, de transformar em "documentos" certos objetos distribuídos de outra maneira. Essa nova distribuição cultural é o primeiro trabalho". Portanto, o exercício historiográfico se fundamenta em dar sentidos aos documentos e fatos vivenciados individual e coletivamente. Por isso, a pesquisa em história:

Consiste em produzir tais documentos, pelo simples fato de recopiar, transcrever ou fotografar esses objetos mudando ao mesmo tempo o seu lugar e o seu estatuto. Esse gesto consiste em "isolar" um corpo, como se faz em física, e em "desfigurar" as coisas para constituí-las como peças que preencham lacunas de um conjunto proposto a priori [...] O material criado por ações combinadas, que o recortam no universo do uso, que vão procurá-lo também fora das fronteiras do uso, e que o destinam a um reemprego coerente. E o vestígio dos atos que modificam uma ordem recebida e uma visão social. (Certeau, 2011, p. 69-70)

A partir dessas ideias, podemos elucidar que o trabalho com a história e historiografia do teatro exige essas diversas ações. Uma das questões enfrentadas é justamente o que fazer com os documentos encontrados. Os sentidos e os caminhos que eles apontam passam a conduzir a produção escrita, pautados na organização, na seleção de dados. Diante do material coletado, o historiador, além de decupar as informações, precisa dar forma, pelo discurso, à sua narrativa. Nesse processo, ele cria, também, séries, esquemas de organização do saber.

O trabalho do historiador abre novas lacunas, ele procura explicar, defender suas ideias sobre os fatos e situações, mas, sua escrita passa a ser caminhos para futuras investigações. Isso ocorre porque sua interpretação histórica passa a ser um caminho de investigação, abrindo outras possibilidades de se perceber os fatos por ele abordados. 


\section{Referências}

BRANDÃO, Tânia. As lacunas e as séries de historiografia nas "Histórias do Teatro no Brasil". In: MOSTAÇO, Edélcio (org.). Para uma história cultural do teatro. Florianópolis/Jaraguá: Design Editora, 2010.

BEZERRA, José Denis de Oliveira. Memórias Cênicas: poéticas teatrais na cidade de Belém (1957-1990). Belém: IAP, 2013.

-----. Vanguardismos e Modernidades: cenas teatrais em Belém do Pará (1941-1968). Belém, 2016. Tese (Doutorado) - Programa de Pós-graduação em História Social da Amazônia, Universidade Federal do Pará.

CERTEAU, Michel de. A escrita da história. Tradução de Maria de Lourdes Menezes. 3 ed. Rio de Janeiro: Forense, 2011.

DORIA, Gustavo. Moderno Teatro Brasileiro. Rio de Janeiro: MEC/SNT, 1975.

FERREIRA, Jerusa Pires. Armadilhas da Memória e outros ensaios, 2 ed. São Paulo: Ateliê Editorial, 2004.

HALBWACHS, Maurice. A memória coletiva. Tradução de Beatriz Sidou. São Paulo: Centauro, 2003.

LE GOFF, Jacques. História e Memória. Tradução Bernardo Leitão - 5 ed. Campinas, SP: Editorada UNICAMP, 2003.

MAGALDI, Sábato. Panorama do Teatro Brasileiro. Rio de Janeiro: Serviço Nacional de Teatro/ FUNARTE, 1979.

PINSKY, Carla Bassanezi; DE LUCA, Tania Regina. O Historiador e suas fontes. São Paulo: Contexto, 2012.

PRADO, Décio de Almeida. História Concisa do Teatro Brasileiro: 1570-1908. São Paulo: Edusp, 2008.

SARGES, Maria de Nazaré. Belém: riquezas produzindo a Belle Époque (1870-1912). 3ed. Belém: Paka-Tatu, 2010.

SALLES, Vicente. Épocas do Teatro no Grão-Pará ou Apresentação do Teatro de Época. Belém: UFPA, 1994.

SALLES, Vicente. A Música e o Tempo no Grão-Pará. Belém: Conselho Estadual de Cultura. Coleção Cultura Paraense, série Theodoro Braga, 1980. 
SILVA, Rose. Histórias invisíveis do Teatro da Paz: da construção à primeira reforma. Belém do Grão-Pará (1869-1890). Belém: Paka-Tatu, 2010.

\section{Sites}

\section{ANPUH}

http://www.snh2011.anpuh.org/simposio/view?ID_SIMPOSIO=521. Acesso em: 21 set. 2016.

\section{ABRACE}

http://portalabrace.org/1/index.php/grupos-de-trabalho/hgf/304-ementa-gt-historia-das-artes-do-espetaculo. Acesso em: 21 set. 2016.

Recebido em: 28/04/2018

Aprovado em: 28/06/2018 